\title{
'||||||||||||||||||||||||||||||||||||||||||||||||||||||||||||||||||.
}

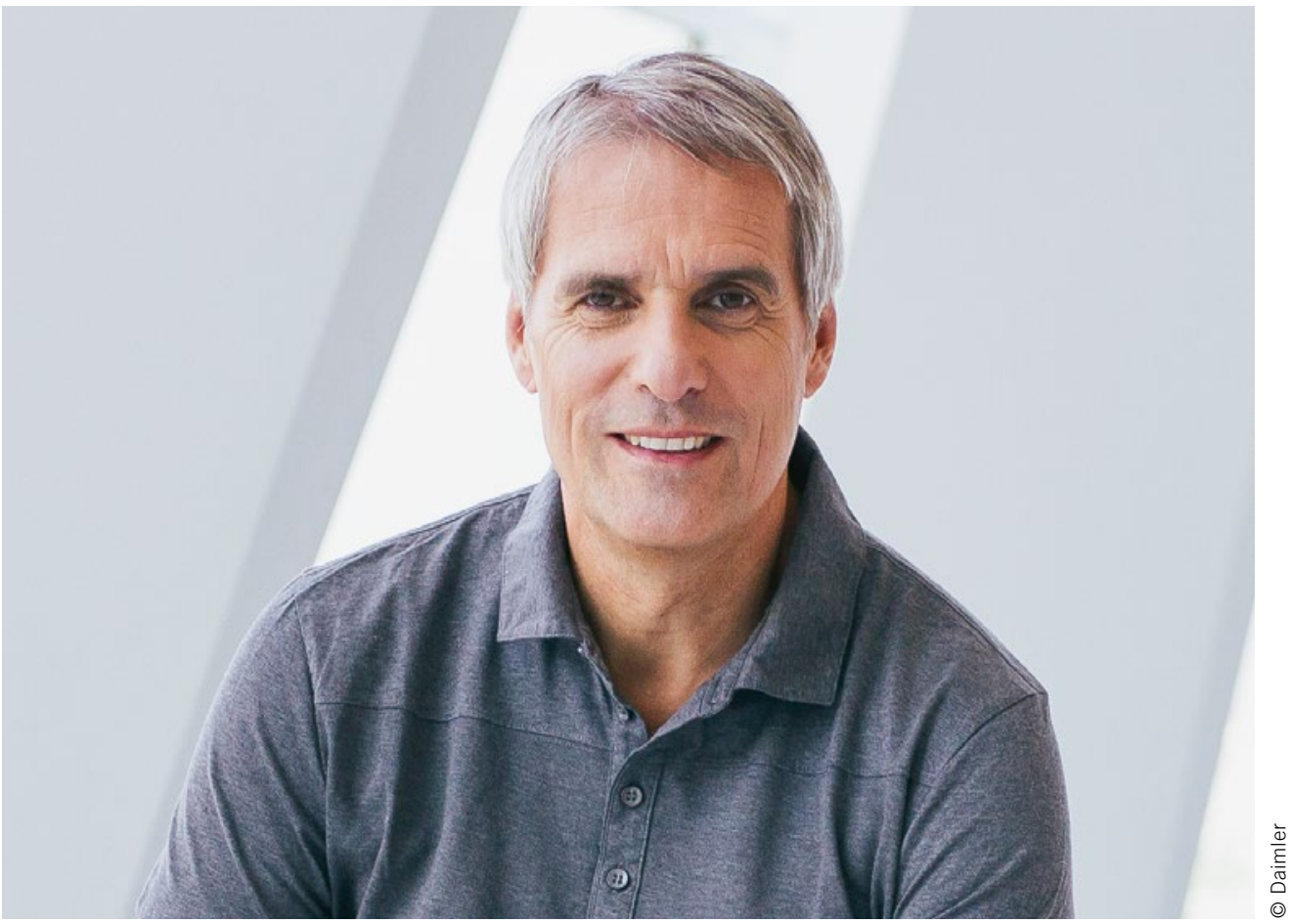

Dipl.-Ing. Wilfried Porth

Vorstandsmitglied der Daimler AG, Personal und Arbeitsdirektor,

Mercedes-Benz Vans

\section{Segel setzen - Kursänderungen als Chance}

Stellen Sie sich vor, Sie planen eine Segeltour zu einem fremden Hafen. Wie gehen Sie vor? Planen Sie vor der Fahrt die Reise, messen den Wind, berechnen den Kurs, binden das Ruder fest und kontrollieren nach Ablauf der für die Reise berechneten Zeit, ob Sie das Ziel erreicht haben? Vermutlich nicht. Wahrscheinlich werden Sie mit einer gewissen Unsicherheit kalkulieren und Ihren Kurs von Zeit zu Zeit anpassen.

Genau diese Fähigkeit, auf veränderte Rahmenbedingungen schnell und selbstgesteuert zu reagieren, bezeichnet man im Unternehmenskontext als Agilität. Für mich ist dies ein wesentlicher Teil unseres Erfolgsrezepts bei Daimler. Agiles Arbeiten erhöht die Innovationsgeschwindigkeit und stärkt die Wettbewerbsfähigkeit in einem komplexen, volatilen Umfeld.

Was ich damit meine: Bei Daimler arbeiten rund 290.000 Menschen aus mehr als 160 Nationen zusammen. Außerdem befindet sich die gesamte Automobilbranche im Umbruch. Digitalisierung, Vernetzung, Elektromobilität, autonomes Fahren, Shared Economy, Mobilität über Apps wie car2go oder moovel - all das verändert die Automobilbranche wie nie zuvor. Diesen Wandel wollen wir aktiv gestalten. Mit unserer strategischen Ausrichtung „Connected, Autonomous, Shared \& Service und Electric Drive“ (Case) stellen wir die Weichen dafür und setzen verstärkt auf neue Formen der Zusammenarbeit.

Agiles Arbeiten zeichnet sich durch große Freiräume in der Arbeitsgestaltung sowie ein hohes Maß an Eigenverantwortung aus. Diese Form der Zusammenarbeit bedarf einer neuen Art von Führung. Anders als bei einer autoritären Führungshaltung übernimmt die Führungskraft in agilen Teams immer stärker die Rolle eines Coaches, der das Team unterstützt, entwickelt und den Rahmen für eigenverantwortliches Handeln schafft.

Für die Entwicklungskollegen heißt das beispielsweise, bestimmte Produkteigenschaften, Funktionalitäten und Kundenerlebnisse klar zu beschreiben, ohne das fertige Produkt zu kennen. Hierfür benötigen Mitarbeiter gute Leitplanken, die ihnen einen vielfältigen Handlungsspielraum eröffnen, in dem sie ihre Ressourcen selbst einsetzen und die notwendigen Entscheidungen treffen, um das nächste Etappenziel selbstständig zu erreichen. So entsteht ein Wechselspiel zwischen Autonomie und Abstimmung mit den verantwortlichen Stakeholdern.

Bei Daimler lernen Führungskräfte, Kontrolle abzugeben und Entscheidungsverantwortung stärker auf den Mitarbeiter zu übertragen. Das erfordert viel Vertrauen - auf beiden Seiten. Jeder Segler weiß, dass es sinnlos ist, ein Boot fix auf einen Zielpunkt auszurichten. Vielmehr geht es um die Kunst, das Ziel im Blick zu haben und den Wind zum Fortkommen zu nutzen. Auch wenn er von der Seite weht oder dreht. 